\title{
OBSERVATIONS ON THE AMINO-ACIDURIA IN MEGALOBLASTIC ANAEMIA
}

\author{
BY \\ DAVID TODD* \\ From the University Department of Medicine, Royal Infirmary, Glasgow
}

(RECEIVED FOR PUBLICATION OCTOBER 8, 1958)

An abnormal excretion of amino-acids in the urine of patients with Addisonian pernicious anaemia in relapse has been reported by Weaver and Neill (1954), by Keeley and Politzer (1956), and by Crane, Hayes, and de Gruchy (1958). Weaver and Neill (1954) stated that in five patients there was an abnormal excretion of taurine with some over-excretion of lysine, cystine, and leucine, while in another with subacute combined degeneration of the spinal cord with no anaemia there was an abnormal excretion of taurine. Keeley and Politzer (1956) confirmed these findings in two patients with Addisonian pernicious anaemia and reported that in seven African patients with non-Addisonian megaloblastic anaemia the urinary amino-acid patterns were normal. On the other hand, Crane et al. (1958), after investigating nine patients with untreated Addisonian pernicious anaemia of whom two had subacute combined degeneration of the spinal cord, concluded that although amino-aciduria did occur there was no characteristic urinary amino-acid pattern in these patients. Moreover, one patient with subacute combined degeneration of the spinal cord showed no abnormal amino-acid excretion. They reported an increased excretion of taurine and $\beta$-amino-iso-butyric acid (BAIB) in about half of their patients, and abnormal traces of aspartic acid, leucine, lysine, phenylalanine, tyrosine, and valine were also present. All three groups of investigators employed paper chromatographic techniques and studied urines only. The present report describes the results of an investigation of the urinary and plasma amino-acid patterns in a comparatively large series of patients with Addisonian pernicious anaemia and other megaloblastic anaemias. An attempt was made to determine the incidence and extent of the amino-aciduria ; the consistency of the abnormal

\footnotetext{
*This investigation was carried out during the tenure of a SinoBritish Fellowship Trust Scholarship.

Present address: Department of Medicine, Queen Mary Hospital, Hong Kong.
}

excretion of taurine; the nature of the aminoaciduria ; and the diagnostic value, if any, of such studies.

\section{MATERIAL AND METHODS}

The patients investigated were of two groups.

Megaloblastic Anaemia Due to Vitamin $B_{12}$ Deficiency

In this group were 22 patients with classical Addisonian pernicious anaemia in whom the diagnosis was made on the finding of a megaloblastic bone marrow, histamine-fast achlorhydria, a low serum vitamin $\mathbf{B}_{12}$ level, and a haematological response to vitamin $B_{12}$. Also included were two patients suffering from the malabsorption syndrome with megaloblastic bone marrow changes, low serum vitamin $B_{12}$ levels, free acid in the gastric juice, and satisfactory haematological responses to vitamin $B_{12}$. All patients were investigated before and after the return of the blood levels to normal after treatment.

\section{Megaloblastic Anaemia of Puerperium/Pregnancy}

There were nine patients in whom only one was first seen before delivery. The diagnosis was based on the findings of a megaloblastic bone marrow, free acid in the gastric juice, a normal serum vitamin $B_{12}$ level, and a satisfactory haematological response to folic acid alone. Seven of these patients were investigated both before treatment and after treatment when the blood levels had returned to normal.

\section{Controls}

Non-anaemic Patients. - Eight haematologically normal patients served as non-anaemic controls. No acutely ill or febrile patient was included.

Anaemic Patients.-This group included :

(i) Five patients with iron-deficiency anaemia from chronic blood loss (three from duodenal ulcer and two from menorrhagia) of whom the two most severely anaemic (haemoglobin $=5.62,5.93$ g. $/ 100$ ml.) were investigated both before and after treatment.

(ii) Two patients with idiopathic hypoplastic anaemia (haemoglobin 5.92 and $6.82 \mathrm{~g} . / 100 \mathrm{ml}$.). 
(iii) Two patients with acute idiopathic acquired haemolytic anaemia (Coombs test positive in both).

(iv) One patient with anaemia due to chronic myeloid leukaemia (haemoglobin $9.47 / 100 \mathrm{ml}$., W.B.C. $340,000 /$ c.mm., and platelets $322,000 /$ c.mm.).

All patients were on the usual hospital diet. Twenty-four hour urine collections were preserved with thymol crystals and refrigerated. Collections were made before the beginning of specific therapy and at different intervals afterwards. A final collection was made when there had been a satisfactory haematological response to therapy. Plasma from heparinized venous blood was obtained both before and after treatment. Heparinized plasma was also separated from bone marrow blood in the course of the diagnostic sternal puncture and a venous blood specimen was obtained at the same time for comparative studies.

The total $\alpha$-amino nitrogen in the 24-hour urine specimens was determined by the formal titration method of Van Slyke and Kirk (1933) taking special precaution to distil off in vacuo all ammonia as tested by red litmus paper.

The individual amino-acids were identified by ascending 2-dimensional paper chromatography employing essentially the technique described by Dent (1951). Whatman No. 1 or No. 4 paper was cut to the size of $30 \times 30 \mathrm{~cm}$. and the two solvents used were water-saturated phenol and lutidine-water. The "2-second" urine (the actual volumes varied from 15 to $50 \mu \mathrm{l}$.) and $625 \mu \mathrm{l}$. of deproteinized (by the addition of 10 volumes of $95 \%$ ethyl alcohol) and electrolytically desalted plasma were the amounts applied for chromatography. Preliminary oxidation with ammonium molybdate and hydrogen peroxide was carried out for the detection of methionine and cystine. The chromatograms were sprayed with an $0.1 \%$ solution of ninhydrin in butanol and developed at $100^{\circ} \mathrm{C}$. for 10 minutes. Heating was found to yield a more complete pattern of ninhydrin-positive spots than developing at room temperature. A rough quantitative estimation of the amino-acids was made by comparison with spots given by $5,10,20,40 \mu \mathrm{g}$. of taurine. One-dimensional runs in butanol-acetic acid-water were examined for the presence of histidine and tyrosine after spraying with Pauly's diazo reagent.

Liver function tests performed included the estimation of serum albumin, globulin, bilirubin, and alkaline phosphatase levels, and the thymol turbidity and colloidal gold flocculation tests.

\section{RESULTS}

\section{Total $\alpha$-Amino Nitrogen in Urine}

The mean total $\alpha$-amino nitrogen concentrations in 24-hour urine collections of the patients so investigated are set out in Table I. The levels in the three groups of anaemic patients before treatment were not significantly different from that of the controls. However, the mean level in
TABLE I

TOTAL URINARY $a$-AMINO NITROGEN EXCRETION IN 24 HOURS IN DIFFERENT PATIENTS

\begin{tabular}{|c|c|c|c|}
\hline & & $\begin{array}{l}\text { No. of } \\
\text { Patients }\end{array}$ & $\begin{array}{c}\text { a-Amino Nitrogen } \\
\text { (mg./24 Hours) }\end{array}$ \\
\hline $\begin{array}{l}\text { Controls } \\
\text { Pernicious anaemia: } \\
\text { (a) Before treatment } \\
\text { (b) After } \\
\text { Iron-deficiency anaemia } \\
\text { Megaloblastic anaemia } \\
\text { puerperium }\end{array}$ & $\begin{array}{l}\cdots \\
\cdots \\
\ddot{\text { of }} \\
\cdots\end{array}$ & $\begin{array}{l}7 \\
9 \\
9 \\
3 \\
3\end{array}$ & 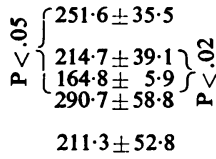 \\
\hline
\end{tabular}

\section{TABLE II}

CONCENTRATIONS OF URINARY AMINO-ACIDS IN EXCESS IN DIFFERENT PATIENTS BEFORE TREATMENT

\begin{tabular}{c|c|c|c}
\hline Patient & $\begin{array}{c}\text { Sex } \\
\text { and } \\
\text { Age }\end{array}$ & $\begin{array}{c}\text { Initial } \\
\text { Haemoglobin } \\
(\mathrm{g} . / 100 \mathrm{ml})\end{array}$ & $\begin{array}{c}\text { Amino-acid in Excess } \\
(\mu \mathrm{g} .)\end{array}$ \\
\hline
\end{tabular}

Addisonian Pernicious Anaemia

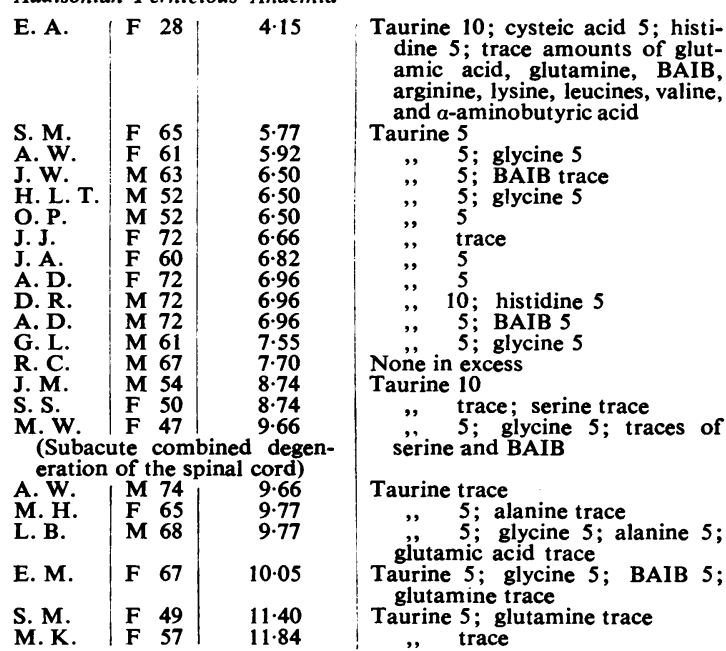

Malabsorption Syndrome and Megaloblastic Anaemia

\begin{tabular}{l|ll|l|l} 
E. M. & F & 58 & 9.92 & Taurine 5; BAIB trace \\
R. E. & M 79 & 11.84 & None in excess
\end{tabular}

Megaloblastic Anaemia of Pregnancy/Puerperium

\begin{tabular}{|c|c|c|c|}
\hline \multicolumn{2}{|c|}{$\underset{\text { M. }}{\text { M. T. }} \mid \underset{\text { Pregnant) }}{\mathbf{F}}$} & $\begin{array}{l}5 \cdot 63 \\
5 \cdot 77\end{array}$ & \multirow{3}{*}{$\begin{array}{l}\text { Taurine trace; BAIB trace } \\
\text { Glycine } 5 ; \text { threonine } 5 ; \text { BAIB } 5 \text {; } \\
\text { traces of alanine and } a \text {-amino- } \\
\text { butyric acid } \\
\text { None in excess } \\
\text { BAIB trace } \\
\text { Traces of taurine and leucines } \\
\text { Traces of taurine, threonine, } \\
\text { BAIB, valine and cysteic acid } \\
\text { None in excess }\end{array}$} \\
\hline $\begin{array}{l}\text { M. G. } \\
\text { I. M. } \\
\text { M. M. } \\
\text { A. C. }\end{array}$ & $\begin{array}{ll}F & 21 \\
F & 29 \\
F & 32 \\
F & 32\end{array}$ & $\begin{array}{l}6.67 \\
6 \cdot 82 \\
7 \cdot 10 \\
7 \cdot 85\end{array}$ & \\
\hline M. D. & F 20 & 10.65 & \\
\hline \multicolumn{4}{|c|}{ Iron-deficiency Anaemia } \\
\hline $\begin{array}{l}\text { M. G. } \\
\text { A. P. }\end{array}$ & $\begin{array}{ll}\mathrm{F} & 25 \\
\mathrm{~F} & 25\end{array}$ & $\begin{array}{l}5.93 \\
5.62\end{array}$ & $\begin{array}{c}\text { Taurine } 5 \\
\quad, \quad 5 ; \text { BAIB trace }\end{array}$ \\
\hline \multicolumn{4}{|c|}{ Acquired Haemolytic Anaemia } \\
\hline M. L. & F 63 & $4 \cdot 44$ & $\begin{array}{l}\text { Taurine trace; traces of threonine, } \\
\text { leucines, phenylalanine, and } \\
\text { valine }\end{array}$ \\
\hline J. $\mathbf{H}$. & & $6 \cdot 22$ & $\begin{array}{l}\text { Taurine 5; BAIB 5; traces of lysine, } \\
\text { serine, and leucine }\end{array}$ \\
\hline
\end{tabular}


the patients with pernicious anaemia after treatment was significantly lower than that encountered in the same patients before treatment and in the controls.

\section{Paper Chromatographic Studies on Urine in Patients}

Megaloblastic Anaemia due to Vitamin $B_{12}$ Deficiency. - The patients with classical Addisonian pernicious anaemia and those with megaloblastic anaemia from vitamin $\mathbf{B}_{12}$ deficiency associated with the malabsorption syndrome are considered as one group because the results they showed were essentially the same (Table II). One patient had the features of subacute combined degeneration of the spinal cord.

The most consistent abnormality in these patients before treatment was an over-excretion of taurine which disappeared after vitamin $B_{12}$ therapy (Fig. 1). This was observed in 22 of the 24 patients. In the other two taurine corresponding to $5 \mu \mathrm{g}$. was present initially but did not show any diminution after treatment; in one the initial haemoglobin level was $11.84 \mathrm{~g} . / 100 \mathrm{ml}$. In four of these patients the 24-hour urines were examined at weekly intervals for four weeks. It was found that by the third week after the start of vitamin $B_{12}$ therapy the urinary chromatogram had assumed the normal pattern and that the decrease in taurine was a consistent feature.

A significant over-excretion of BAIB, glycine, glutamine, glutamic acid, histidine, serine, and alanine singly or in various combinations was present in seven of the 24 patients (Table II). However, a generalized amino-aciduria occurred in one only (E. A., F., 28) and this patient had the lowest haemoglobin level $(4.15 \mathrm{~g} . / 100 \mathrm{ml}$.) in the present series. An excess of BAIB was present in only six of the 24 patients, although marked anorexia was admitted by 22 of the 24 patients. This is at variance with the suggestion of Crane et al. (1958) that increased BAIB excretion in these patients may be the result of anorexia and general malaise. The increased amounts of glycine and histidine sometimes observed in the chromatograms in some patients before treatment may be attributed to variations in diet and are probably of no real significance.

There was no correlation between the degree of anaemia and the amino-aciduria with the exception that the most profoundly anaemic patient showed the most generalized amino-acid over-excretion. There was no correlation between the level of serum vitamin $B_{12}$ and the extent of the amino-aciduria. Liver function tests performed in seven of these 10 patients were normal and these seven included the most

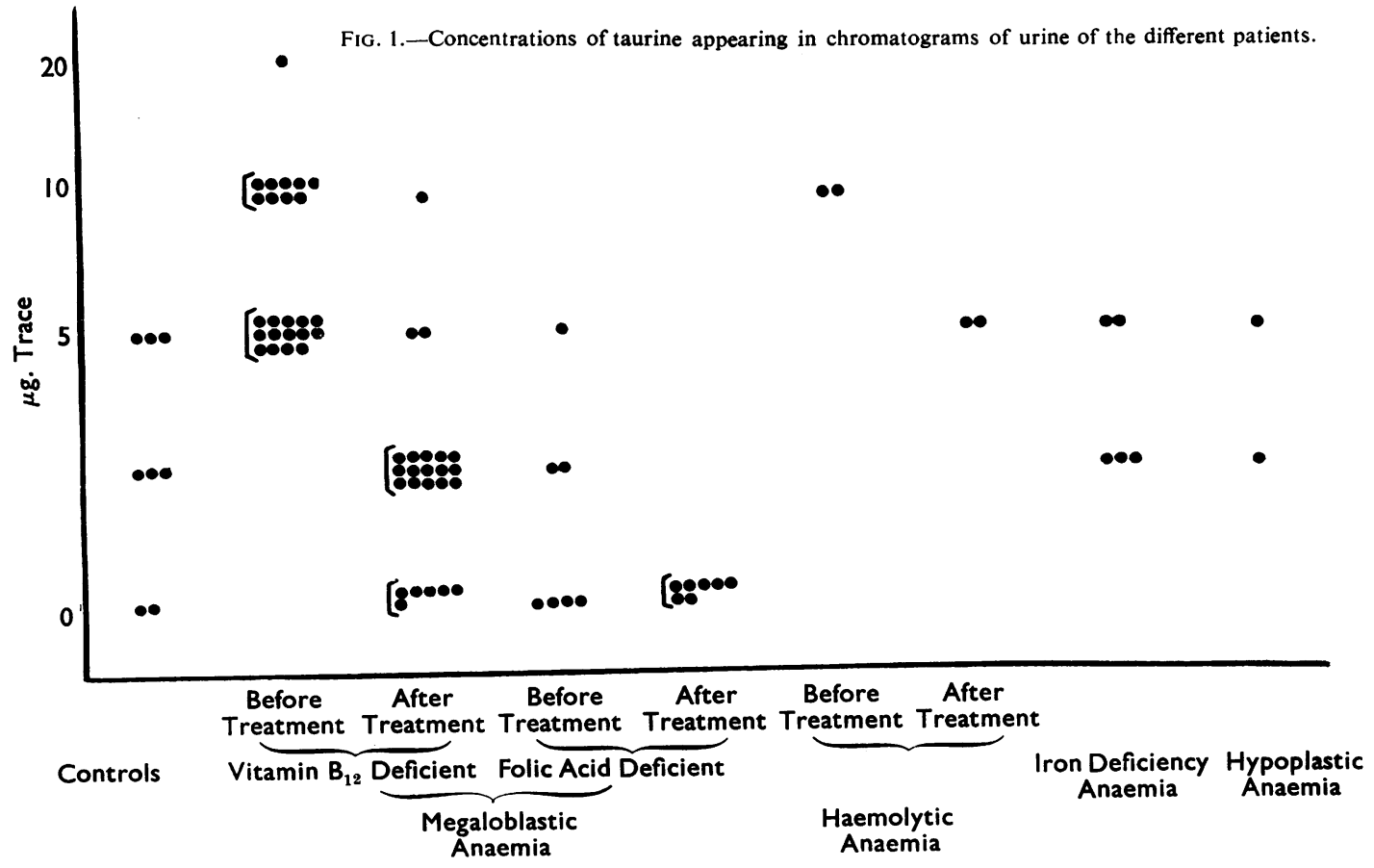


profoundly anaemic patient (E.A., F., 28). There was a slight rise in globulin in the other three patients and of these one had a positive thymol turbidity test. However, they (A. D., F., 72 ; D. R., M., 72 ; and A. D., M., 72) did not show urinary amino-acid excretion patterns significantly different from those of the others.

Megaloblastic Anaemia of Puerperium/ Pregnancy.-Of the nine patients investigated, three showed no abnormality in the urinary amino-acid patterns. Only seven of these nine patients were investigated both before and after treatment (Table II). One of the patients (M. C., F., 30) was pregnant when first seen and the amino-aciduria detected may have been wholly or in part attributable to the pregnancy (Wallraff, Brodie, and Borden, 1950). Of the remaining six patients, one had abnormal features in the liver function tests (M. T., F., 29: thymol turbidity= 9 Maclagan units, serum albumin low), but it is unlikely that this was responsible for the slight increase in excretion of taurine and BAIB, for these disappeared after treatment with folic acid while the liver function tests remained abnormal. Furthermore, the liver function tests were normal in two of the other patients (I. M., F., 29, and M. M., F., 32). It is not known whether or not amino-aciduria is present in the puerperium which might account for the slight increases in BAIB, taurine, cystine, leucine, and/or valine encountered. An interesting feature was that taurine was not detected in six of the nine patients before treatment and that when present it was never as great in amount as that observed in the patients with pernicious anaemia (Fig. 1). After treatment taurine was no longer detected in any of the chromatograms.

As in the patients with pernicious anaemia there was no apparent correlation between the severity of the anaemia and the appearance of amino-aciduria, but the relatively small number of patients and similarities in their haemoglobin levels do not permit of a definite conclusion.

\section{Paper Chromatographic Studies in Controls}

Non-anaemic Patients.-The chromatograms of the urine from these patients were similar to those described as occurring in the normal by Walshe (1953) and Dent (1954), and showed glycine as the predominant spot with smaller amounts of histidine, alanine (in six), taurine (in six), glutamic acid (in five), cysteic acid, traces only (in five), methyl histidine (in three), BAIB (in two), and glutamine (in one). The intensity of the taurine spot in no instance exceeded that corresponding to $5 \mu \mathrm{g}$. of pure taurine.

\section{Anaemic Patients.-}

(i) Iron-deficiency Anaemia.-There were no abnormal features in the urinary amino-acid patterns in three patients with haemoglobin levels above 9 g. $/ 100 \mathrm{ml}$. On the other hand, two patients with haemoglobin levels below $6 \mathrm{~g}$./ $100 \mathrm{ml}$. showed a slightly increased excretion of taurine and this was associated with a slight increase in BAIB in one (Table II). These diminished with adequate iron therapy. Both had normal serum vitamin $\mathrm{B}_{12}$ levels.

(ii) Aplastic Anaemia.-In the two patients investigated there was no abnormality in the urinary amino-acid patterns. In one taurine was detected in normal amounts.

(iii) Acquired Haemolytic Anaemia.-The two patients investigated both showed a mild generalized amino-aciduria (Table II). In both the amino-aciduria diminished as the haemoglobin increased following prednisone therapy. In one the urinary amino-acid pattern became normal, but in the other, in whom the haemolytic process was less satisfactorily controlled, the amino-aciduria diminished but did not completely disappear. In this latter patient the bone marrow was initially megaloblastic with a normal serum vitamin $B_{12}$ level of $120 \mu \mu \mathrm{g} . / \mathrm{ml}$. Liver function tests were performed in one of these patients (J.H., F., 61), and the results were normal apart from a bilirubinaemia.

(iv) Chronic Myeloid Leukaemia. - The chromatogram of this patient's urine showed a normal amino-acid pattern and no taurine.

\section{Chromatographic Studies on Venous Blood Plasma}

The plasma from eight patients with pernicious anaemia examined by paper chromatography both before and after treatment showed no significant difference in the amino-acid patterns. Only trace amounts of taurine were detected, and in no instance was it greater than $5 \mu \mathrm{g}$. Furthermore, these plasma chromatograms did not differ significantly from those of four normal controls, two patients with megaloblastic anaemia of puerperium, two patients with iron deficiency anaemia, and two patients with acquired haemolytic anaemia.

On the other hand, the plasma chromatogram of the patient with chronic myeloid leukaemia revealed an excess of taurine and glutamic acid (Table III). This latter finding is in accordance with the report by Kelley and Waisman (1957) that in chronic myeloid leukaemia the plasma glutamic acid may be increased. It should be 
noted, however, that the chromatogram of this patient's urine did not reveal the presence of taurine (v. supra).

\section{Chromatographic Studies on Bone Marrow Blood Plasma}

The plasma from bone marrow blood of seven patients was examined chromatographically and compared with the chromatograms of plasma from peripheral venous blood withdrawn at the same time. The results show that with the exception of taurine and glutamic acid the aminoacid patterns were the same. These two aminoacids gave much larger spots in the chromatograms of the marrow plasma than in those of the venous plasma (Table III). This increase in taurine and glutamic acid was the same in the

TABLE III

CONCENTRATIONS OF TAURINE AND GLUTAMIC ACID IN BONE MARROW PLASMA AND VENOUS BLOOD PLASMA IN DIFFERENT PATIENTS

\begin{tabular}{|c|c|c|c|c|}
\hline & \multicolumn{2}{|c|}{$\underset{(\mu \mathrm{g} .)}{\text { Taurine }}$} & \multicolumn{2}{|c|}{$\underset{(\mu \mathrm{g} .)}{\text { Glutamic Acid }}$} \\
\hline & $\begin{array}{l}\text { Marrow } \\
\text { Plasma }\end{array}$ & $\begin{array}{l}\text { Venous } \\
\text { Plasma }\end{array}$ & $\begin{array}{l}\text { Marrow } \\
\text { Plasma }\end{array}$ & $\begin{array}{l}\text { Venous } \\
\text { Plasma }\end{array}$ \\
\hline 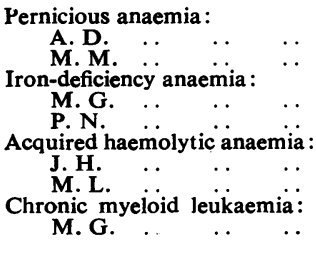 & $\begin{array}{r}5 \\
5 \\
10 \\
10 \\
10 \\
5 \\
>40\end{array}$ & $\begin{array}{c}\text { Trace } \\
\text {," } \\
\text {," } \\
\text {," } \\
\text { ", }\end{array}$ & $\begin{array}{r}20 \\
20 \\
10 \\
20 \\
20 \\
10 \\
>40\end{array}$ & $\begin{array}{c}5 \\
\text { Trace } \\
, " \\
, \\
, " \\
>40\end{array}$ \\
\hline
\end{tabular}

patients with pernicious anaemia, iron-deficiency anaemia, and acquired haemolytic anaemia, but was more marked in the marrow plasma of the patient with chronic myeloid leukaemia.

The significance of these results is uncertain. While it is admitted that there was no means by which one could aspirate amounts of bone marrow comparable in cellular and plasma content each time, the consistency of the finding of an increase in taurine and in glutamic acid is of interest. However, it is felt that this may be attributable to the larger amounts of leucocytes and platelets in the marrow as compared with peripheral blood, and to the slight haemolysis that occurred in the course of handling of the marrow specimens. This is suggested by the report of McMenamy, Lund, and Oncley (1957) that leucocytes and platelets contain a large amount of taurine and that glutamic acid may leak from erythrocytes during the handling of whole blood. The findings in the marrow plasma from the patient with chronic myeloid leukaemia (Table
III) in which there were greatly increased numbers of leucocytes and platelets further support this contention.

\section{DISCUSSION}

The results of the total urinary $\alpha$-aminonitrogen estimations show that this is not significantly increased in patients with megaloblastic anaemia from either vitamin $B_{12}$ or folic acid deficiency. Therefore the chromatographic results may be interpreted as showing qualitative rather than quantitative changes in the urinary amino-acids. However, this does not indicate that the excretion of individual amino-acids may not be in excess of normal, and although paper chromatographic studies are at best only semi-quantitative the results of the present investigation suggest that this does occur. The significantly lower excretion of total $\alpha$-amino nitrogen in the urine of the patients with pernicious anaemia after treatment may be the result of the nitrogen retention which occurs in these patients following effective therapy (Baldbridge and Barer, 1931).

Analysis of the results suggests that in the patients with vitamin $\mathrm{B}_{12}$ deficiency there are two abnormalities in the urinary amino-acid excretion pattern. The most consistent of these, occurring in 22 of the 24 patients investigated, was an overexcretion of taurine and this is in accord with reports by Weaver and Neill (1954), Keeley and Politzer (1956), and Crane et al. (1958). This over-excretion of taurine occurred alone or in association with an over-excretion of other amino-acids. It was not encountered in other patients with comparable degrees of anaemia, with the exception of patients with acute idiopathic haemolytic anaemia where it occurred together with a generalized amino-aciduria. The second abnormality, encountered in only seven of the 24 patients, consisted of a slight but significant overexcretion of BAIB, glycine, histidine, glutamine, alanine, glutamic acid, and serine in varying combinations amounting to a generalized aminoaciduria in the most severely anaemic patient. This abnormality was also present in the patients with megaloblastic anaemia of puerperium/ pregnancy and acquired haemolytic anaemia, and to a lesser extent in a patient with severe irondeficiency anaemia (Table II). It was not encountered in the two patients with hypoplastic anaemia.

The cause of the over-excretion of taurine in these patients with vitamin $B_{12}$ deficiency is uncertain. The presence of a larger amount of 
taurine in marrow plasma when compared with venous plasma has been discussed and attributed to contamination by the larger number of leucocytes and platelets in the former. It is possible that it was due to hepatic dysfunction. The normal plasma taurine levels do not exclude this, for, according to Dent (1958), plasma levels of taurine are normally low and difficult to detect chromatographically, and as renal taurine clearance is very high it is possible to have an overflow taurinuria with very little detectable in the blood plasma. However, there was no correlation between abnormal liver function tests and the increase in urinary taurine, and furthermore there was no excess excretion of cystine described as occurring in hepatic disease (Walshe, 1953). Another possible mechanism in the increase in urinary taurine is that it was due to a renal tubular defect. This seems unlikely as it would have then occurred as an isolated urinary taurinuria often marked and yet unassociated with over-excretion of other amino-acids. According to Dent (1958) taurine may be excreted in increased amounts in conditions associated with a negative nitrogen balance which has been reported to occur in patients with pernicious anaemia (Alt, 1929). This may account in part for the present findings and may also explain the increased taurine excretion in the patients with severe iron-deficiency anaemia. However, that this is probably not the entire explanation is shown by the absence of a comparable increase in taurine excretion in the patients with megaloblastic anaemia of the puerperium, when a negative nitrogen balance is often present (Cantarow and Trumper, 1949). Crane et al. (1958) suggested, on the basis of the report by Jukes, Stokstad, and Broquist (1950) that in chicks vitamin $B_{12}$ may be required for the transformation of homocysteine to methionine, that a lowered rate of synthesis of methionine due to vitamin $B_{12}$ deficiency may result in an enhanced urinary excretion of taurine through degradation of accumulated homocysteine in the body (Eldjarn, 1954). It is at present considered that this, together with a negative nitrogen balance, may be the explanation for the increased urinary taurine observed in these patients with vitamin $B_{12}$ deficiency.

The increased taurine excretion in the patients with acute acquired haemolytic anaemia was not related to vitamin $B_{12}$ deficiency, for in both the serum vitamin $B_{12}$ levels were over $100 \mu \mu \mathrm{g} . / \mathrm{ml}$. In all probability it occurred as part of a generalized amino-aciduria.
An over-excretion of one or more of the other amino-acids was present in only seven of the 24 patients with vitamin $\mathbf{B}_{12}$ deficiency, but this was not characteristic of this group as it also occurred in patients with a megaloblastic anaemia of the puerperium/pregnancy, acquired haemolytic anaemia, and, to a lesser degree, in severe irondeficiency anaemia. The arguments against this being the result of bone marrow or hepatic dysfunction are the same as those discussed in connexion with taurine. In the patient first seen in pregnancy the amino-aciduria may have been due to the pregnancy (Wallraff et al., 1950). In the puerperal patient the mild amino-aciduria was probably not due to the puerperium because in two patients (M. G., F., 21 ; M. D., F., 20) both first seen within three weeks of delivery there was no abnormality in the urinary chromatograms (Table II). Anaemia alone does not appear to be the explanation, for there was no amino-aciduria in the patients with aplastic anaemia and comparable haemoglobin levels.

In view of the normal plasma concentration of the amino-acids detected in excess in the urine of these patients, it seems reasonable to suggest that the amino-aciduria encountered was of renal origin. Renal tubular dysfunction has been described in severe Addisonian pernicious anaemia by Stieglitz (1924) and in acute haemolytic anaemia by Dacie (1954), and that renal tubular dysfunction may result in amino-aciduria of varying degrees can be concluded from the reports by Spencer and Franglen (1952), Wilson, Thompson, and Dent (1953), Pare and Sandler (1954), and Marsden and Wilson (1955). In this connexion the report of renal amino-aciduria in ascorbic acid deficiency by Jonxis and Huisman (1954) is of interest, for ascorbic acid is intimately related to amino-acid metabolism (Bicknell and Prescott, 1953). The presence of amino-aciduria in the less severely anaemic patients is not so readily explained by renal tubular dysfunction, but it may well be that the primary defect is a disorder in amino-acid metabolism at a cellular level involving body cells in general and that the demonstration of amino-aciduria is merely due to the accessibility of the kidneys by means of urinary examination. It has been shown that there is a close relation between amino-acid metabolism and erythropoiesis, although the precise role of each amino-acid is yet to be determined (Wintrobe, 1956). Therefore, while the underlying mechanism for the amino-aciduria in these patients with abnormal erythropoiesis remains uncertain, it is suggested that it is a 
manifestation of a general disturbance in aminoacid utilization and degradation in the cells of the body as a whole.

The reports of Weaver and Neill (1954) and Keeley and Politzer (1956) suggested that paper chromatography of urine may afford a means by which megaloblastic anaemia from vitamin $\mathbf{B}_{12}$ deficiency could be differentiated from that due to folic acid deficiency. The present findings indicate that the demonstration of a mild aminoaciduria is specific neither for vitamin- $\mathrm{B}_{12}{ }^{-}$ deficient nor folic-acid-deficient patients. It may or may not be present in either. The results would be even more difficult to interpret in pregnancy when a megaloblastic anaemia sometimes develops and the question of choice of treatment with either vitamin $B_{12}$ or folic acid arises. As to the increase in taurine excretion, reference to Fig. 1 shows that this occurs regularly in patients with $B_{12}$ deficiency, and not in those deficient in folic acid. Therefore the demonstration of a large taurine spot of over $5 \mu \mathrm{g}$. intensity would favour the diagnosis of vitamin $B_{12}$ deficiency in a patient with megaloblastic anaemia. However, prediction in the individual case may be open to fallacies as there is some overlapping amongst those with smaller degrees of taurinuria (Fig. 1). Moreover, taurine over-excretion may occur in a variety of conditions such as fever, cancer, and wasting diseases (Dent, 1958) and in acute acquired haemolytic anaemia. It is, therefore, concluded that when marked taurine excretion is encountered in a patient with megaloblastic anaemia the diagnosis of primary vitamin $B_{12}$ deficiency rather than folic acid deficiency may be made provided all other causes of increased urinary taurine excretion can be ruled out.

Lastly, the urinary amino-acid pattern of the only patient in this series with subacute combined degeneration of the spinal cord was not different from that encountered in patients with Addisonian pernicious anaemia without neurological complications. Unfortunately no patient suffering from subacute combined degeneration of the spinal cord without anaemia was investigated.

\section{SUMMARY AND CONCLUSIONS}

The 24-hour excretion of total $\alpha$-amino nitrogen was normal in patients with megaloblastic anaemia due to vitamin $B_{12}$ deficiency (Addisonian pernicious anaemia and the malabsorption syndrome) and folic acid deficiency (anaemia of pregnancy and the puerperium) before treatment.
The mild amino-aciduria encountered before treatment in megaloblastic anaemia due to vitamin $B_{12}$ deficiency was non-specific and occurred to a similar degree in megaloblastic anaemia due to folic acid deficiency and in acute acquired idiopathic haemolytic anaemia.

An increase in urinary taurine occurred more regularly and was more pronounced in megaloblastic anaemia due to vitamin $B_{12}$ deficiency before treatment, and, if interpreted with caution, may be helpful in differentiating it from megaloblastic anaemia due to folic acid deficiency.

The mild amino-aciduria and increase in urinary taurine decreased after specific therapy.

The possible causes of the amino-aciduria are discussed.

I should like to thank Professor L. J. Davis for his encouragement and interest in this work and Professor C. E. Dent for his advice and criticism throughout the course of the study. I am also indebted to Dr. J. C. Eaton for the use of apparatus in his Department; to Dr. James Laurie, of the Dumfries and Galloway Royal Infirmary, and Dr. J. W. Macfarlane, M.C., of the Glasgow Royal Infirmary, for permission to investigate patients under their care, and to Dr. S. G. McAlpine and Dr. W. R. Murdoch for their kind co-operation. Part of the expense of this investigation was borne by the Rankin Fund of the University of Glasgow.

\section{REFERENCES}

Alt, H. L. (1929). Arch. intern. Med., 43, 488.

Baldridge, C. W., and Barer, A. (1931). J. clin. Invest., 10, 529.

Bicknell, F., and Prescott, F. (1953). The Vitamins in Medicine, 3rd ed., p. 427. William Heinemann, London.

Can tarow, A., and Trumper, M. (1949). Clinical Biochemistry, 4th ed., p. 89. W. B. Saunders, London.

Crane, C. W., Hayes, R. A., and Gruchy, G. L. de (1958). J. clin. Path., 11, 162.

Dacie, J. V. (1954). The Haemolytic Anaemias: Congenital and Acquired, p. 181. J. \& A. Churchill, London.

Dent, C. E. (1951). In Recent Advances in Clinical Pathology, 2nd ed., p. 238, ed. S. C. Dyke. J. \& A. Churchill, London.

(1954). In Lectures on the Scientific Basis of Medicine, 1952-53, Vol. 2, p. 213. Athlone Press, London. (1958). Personal communication.

Eldjarn, L. (1954). Scand. J. clin. Lab. Invest., 6, Suppl. 13.

Jonxis, J. H. P., and Huisman, T. H. J. (1954). Pediatrics, 14, 238.

Jukes, T. H., Stokstad, E. L. R., and Broquist, H. P. (1950). Arch. Biochem., $25,453$.

Keeley, K. J., and Politzer, W. M. (1956). J. clin. Path., 9, 142.

Kelley, J. J., and Waisman, H. A. (1957). Blood, 12, 635.

McMenamy, R. H., Lund, C. C., and Oncley, J. L. (1957). J. clin. Invest., 36, 1672.

Marsden, H. B., and Wilson, V. K. (1955). Brit. med. J., 1, 324.

Pare, C. M. B., and Sandler, M. (1954). Lancet, 1, 702.

Spencer, A. G., and Franglen, G. T. (1952). Ibid., 1, 190.

Stieglitz, E. J. (1924). Arch. intern. Med., 33, 58.

Van Slyke, D. D., and Kirk, E. (1933). J. biol. Chem., 102, 651.

Wallraff, E. B., Brodie, E. C., and Borden, A. L. (1950). J. clin. Invest., 29, 1542.

Walshe, J. M. (1953). Quart. J. Med., n.s. 22, 483.

Weaver, J. A., and Neill, D. W. (1954). Lancet, 1, 1212.

Wilson, V. K., Thompson, M.L., and Dent, C. E. (1953). Ibid., 2, 66.

Wintrobe, M. M. (1956). Clinical Hematology, 4th ed., p. 140. Lea and Febiger, Philadelphia. 